\title{
Role of Serotonin and Noradrenaline in the Rapid Antidepressant Action of Ketamine
}

\author{
Xavier López-Gil,,$^{\dagger}$ Laura Jiménez-Sánchez, ${ }^{\ddagger}$ Leticia Campa, ${ }^{\ddagger}$, Elena Castro, ${ }^{\S}, \|, \perp$ Clara Frago, ${ }^{\perp}$ \\ and Albert Adell* ${ }^{*},, \perp^{(0)}$

\begin{abstract}
${ }^{\dagger}$ Experimental 7T MRI Unit, Institut d’Investigacions Biomèdiques August Pi i Sunyer (IDIBAPS), Barcelona 08036, Spain Barcelona 08036, Spain

${ }^{\S}$ Centro de Investigación Biomédica en Red de Salud Mental (CIBERSAM), Madrid 28029, Spain

"Departamento de Fisiología y Farmacología, Facultad de Medicina, Universidad de Cantabria, Santander 39011, Spain

${ }^{\perp}$ Instituto de Biomedicina y Biotecnología de Cantabria, IBBTEC (CSIC, Universidad de Cantabria), Santander 39011, Spain
\end{abstract} \\ ${ }^{*}$ Department of Neurochemistry and Neuropharmacology, Instituto de Investigaciones Biomédicas de Barcelona, CSIC, IDIBAPS,
}

Supporting Information

\begin{abstract}
Depression is a chronic and debilitating illness that interferes severely with many human behaviors, and is the leading cause of disability in the world. There is data suggesting that deficits in serotonin neurotransmission can contribute to the development of depression. Indeed, $>90 \%$ of prescribed antidepressant drugs act by increasing serotonergic transmission at the synapse. However, this increase is offset by a negative feedback operating at the level of the cell body of the serotonin neurons in the raphe nuclei. In the present work, we demonstrate: first, the intracortical infusion of ketamine induced an antidepressant-like effect in the forced swim test, comparable to that produced by systemic ketamine; second, systemic and intracortical ketamine increased serotonin and noradrenaline efflux in the prefrontal cortex, but not in the dorsal raphe nucleus; third, systemic and intracortical

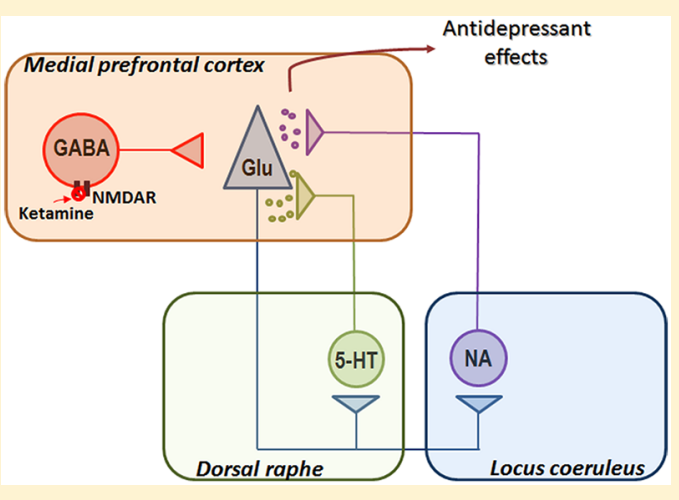
administration of ketamine increased the efflux of glutamate in the prefrontal cortex and dorsal raphe nucleus; fourth, systemic ketamine did not alter the functionality of $5-\mathrm{HT}_{1 \mathrm{~A}}$ receptors in the dorsal raphe nucleus. Taken together, these findings suggest that the antidepressant-like effects of ketamine are caused by the stimulation of the prefrontal projection to the dorsal raphe nucleus and locus coeruleus caused by an elevated glutamate in the medial prefrontal cortex, which would stimulate release of serotonin and noradrenaline in the same area. The impact of both monoamines in the antidepressant response to ketamine seems to have different time frames.
\end{abstract}

KEYWORDS: Depression, raphe, serotonin, noradrenaline, glutamate

\section{INTRODUCTION}

Major depression, the most common of the psychiatric illnesses, is a severe and deteriorating condition that impacts several brain areas, impairing their normal functioning, for instance, nucleus accumbens (reward and motivation), amygdala (fear and anxiety), limbic system (sad mood), prefrontal cortex (cognitive impairment), and hypothalamus (vegetative symptoms). The serotonergic system originated in the dorsal raphe nucleus (DRN), through its vast innervation of all these brain regions, is in a critical position to influence these different behaviors and, therefore, has been implicated in the etiology of depression and its treatment. ${ }^{1,2}$ Likewise, the noradrenergic neurons concentrated in the nucleus locus coeruleus ${ }^{3}$ are also relevant to the pharmacotherapy of depression. ${ }^{4}$ Although much has been discussed in favor of or against a role of serotonin and/or noradrenaline in depression, it is indisputable that $>90 \%$ of prescribed antidepressant drugs, the selective serotonin reuptake inhibitors (SSRIs) and the selective noradrenaline and serotonin uptake inhibitors (SNRIs), act by increasing these transmitters at the synapse. Interestingly, the sustained effect of recent antidepressant therapies, deep brain stimulation (DBS) and ketamine, seems to depend on an intact serotonin system in the brain. ${ }^{5-7}$ However, despite the widespread use of SSRIs and SNRIs to treat depression, there is a lack of compelling evidence linking depression to low serotonergic and/or noradrenergic transmission.

Two of the principal limitations of current antidepressant drugs are their insufficient efficacy and therapeutic delay. Indeed, it is estimated that one-third of patients do not respond adequately to such medications. ${ }^{8,9}$ Even when there is a positive

Special Issue: Serotonin Research 2018

Received: May 16, 2019

Accepted: June 5, 2019

Published: June 5, 2019 
response, all available antidepressant drugs need to be administered for weeks or months to evoke a significant clinical improvement (i.e., 50\% reduction of severity). More than two decades ago, our lab demonstrated for the first time that available antidepressant drugs increased the release of serotonin predominantly in the raphe region. ${ }^{10}$ This excess of extracellular serotonin therein would stimulate raphe $5-\mathrm{HT}_{1 \mathrm{~A}}$ autoreceptors, ${ }^{10,11}$ thus leading to a reduced firing activity of serotonergic cells, with the consequent decrease of forebrain release of serotonin, an effect contrary to that required for the therapeutic response. $^{12,13}$ Accordingly, it was proposed that a therapy that combined an SSRI with a $5-\mathrm{HT}_{1 \mathrm{~A}}$ receptor antagonist, would reduce the latency of the antidepressant response. ${ }^{14}$ This was later confirmed in part by several clinical studies ${ }^{15}$ (see ref 16 for review). However, the add-on use of $5-\mathrm{HT}_{1 \mathrm{~A}}$ receptor antagonists failed to be advantageous to treat depression because the activation of forebrain $5-\mathrm{HT}_{1 \mathrm{~A}}$ receptors is necessary for an antidepressant response ${ }^{17}$ and, in fact, prefrontal $5-\mathrm{HT}_{1 \mathrm{~A}}$ receptors have been reported to play a role in the antidepressant response to ketamine. ${ }^{18}$ In line with these findings, recent preclinical work has shown that mice that overexpress $5-\mathrm{HT}_{1 \mathrm{~A}}$ receptors in the raphe region exhibit no behavioral response to antidepressant treatment. ${ }^{19}$ In contrast, the selective reduction of the expression of presynaptic (raphe autoreceptor), but not postsynaptic (forebrain heteroreceptor) $5-\mathrm{HT}_{1 \mathrm{~A}}$ receptors by the use of small-interfering RNA (siRNA) targeted to serotonin neurons evoked strong antidepressant-like effects. ${ }^{20}$ However, this strategy has not been tested so far in the clinical setting.

In the past decade, clinical investigations have shown that the $\mathrm{N}$-methyl-D-aspartate (NMDA) receptor antagonist, ketamine, produced a rapid (in only $2 \mathrm{~h}$ after a single intravenous bolus administration) and sustained (lasting up to 7 days) antidepressant action. ${ }^{21-24}$ This finding has shaken up the field of pharmacotherapy for depression, thus evidencing that a faster antidepressant response is eventually possible. Although the mechanism of action of ketamine remains poorly understood, the involvement of several cellular processes has been uncovered. For instance, the rapid antidepressant-like action of ketamine requires the activation of a class of ionotropic glutamate receptors, the $\alpha$-amino-3-hydroxy-5-methyl-4-isoxazolepropionic acid (AMPA) receptors, ${ }^{25-27}$ and the stimulation of mammalian target of rapamycin (mTOR), an intracellular pathway associated with synaptic plasticity. ${ }^{28}$ Ketamine microinfusion into the infralimbic cortex reproduced the antidepressant-like actions of systemic ketamine 29,30 and the muscimolinduced neuronal inactivation of the infralimbic prefrontal cortex fully blocked these behavioral effects of systemic ketamine. ${ }^{29}$ Further, the direct stimulation of AMPA receptors in the medial prefrontal cortex (mPFC) by the full agonist $(S)$ AMPA also exerted an antidepressant response and increased the prefrontal efflux of 5-HT and glutamate. ${ }^{31,32}$ We have also shown that both systemic and bilateral (but not unilateral), intra-mPFC administration of ketamine increased serotonin efflux in the mPFC. ${ }^{33,34}$ However, infusion of ketamine into the DRN did not alter 5-HT efflux in the mPFC. ${ }^{35}$ Overall this set of results seems to support the idea that prefrontal (infralimbic) 5HT might contribute to the antidepressant-like effects of ketamine. Interestingly, we recently described that DBS of the infralimbic $\mathrm{mPFC}$ was able to release glutamate in the DRN, which in turn stimulated serotonin neurons in a way that 5-HT release occurred in the $\mathrm{mPFC}$ (terminal release) but not in the DRN (somatodendritic release), ${ }^{31}$ thus precluding feedback inhibition of 5-HT cells by activation of $5-\mathrm{HT}_{1 \mathrm{~A}}$ autoreceptors.
This was consistent with the results obtained after the optogenetic stimulation of layer five pyramidal neurons of the mPFC $^{29,36-38}$ and would ultimately contribute to the rapid antidepressant-like response. Altogether, the important question that emerged was: what is the precise mechanism by which the stimulation of cortico-raphe projection (brought about by DBS, optogenetics or ketamine) evokes a rapid antidepressant response associated with increased prefrontal 5-HT? To solve this issue, we first examined whether the intra-mPFC infusion reproduced the antidepressant-like effects of systemic ketamine. Second, we asked whether ketamine could affect noradrenaline, 5-HT, and glutamate efflux in the mPFC and DRN.

\section{RESULTS}

Effects of Ketamine on the FST. As depicted in Figure 1, one-way ANOVA showed that the administration of ketamine

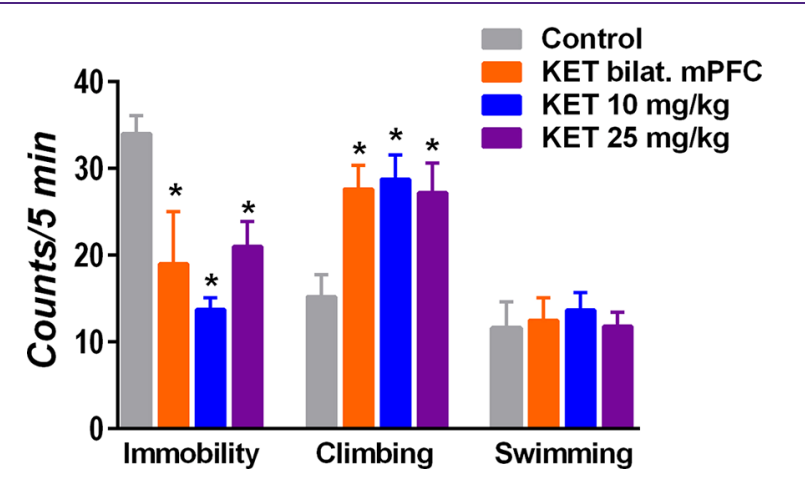

Figure 1. Antidepressant-like effects of bilateral intra-mPFC and i.p. administration of ketamine (KET). Both intra-mPFC $(300 \mu \mathrm{M})$ and systemic (10 and $25 \mathrm{mg} / \mathrm{kg}$ ) ketamine decreased immobility and increased climbing with respect to control group in the forced swim test. $* p<0.05$, post hoc Dunnett's multiple comparison tests following significant ANOVA; $4-6$ animals per group.

through both routes decreased immobility $\left(F_{3,12}=7.576\right.$; $p<$ $0.005)$ and increased climbing $\left(F_{3,13}=4.784 ; p<0.02\right)$ in the FST without changing swimming behavior. This decreased immobility was brought about without significant changes in locomotor activity (Figure S1). Also, as noted in a previous study, the intra-mPFC perfusion of ketamine did not produced hyperlocomotion. $^{34}$

Effects of Ketamine on 5-HT, Noradrenaline, and Glutamate Efflux. In the different experimental conditions of this work no significant differences among the basal extracellular levels of 5-HT, noradrenaline and glutamate in the MPFC and DRN were observed. Therefore, data was pooled and shown in Table S1. Two-way repeated measures ANOVA showed that the systemic administration of ketamine dose-dependently increased 5-HT in the mPFC (Figure 2A) as demonstrated by a significant effect of dose $\left(F_{2,15}=6.633, p<0.01\right)$, time $\left(F_{9,135}=\right.$ $10.247, p<0.0001)$, and treatment $\times$ time interaction $\left(F_{18,135}=\right.$ $4.191, p<0.0001)$. The increase of prefrontal 5-HT elicited by the dose of $25 \mathrm{mg} / \mathrm{kg}$ of ketamine was higher than that of $10 \mathrm{mg} /$ $\mathrm{kg}(p<0.03)$. Results expressed in area under the curve (AUC) of the same treatments are represented in Figure 2B. In contrast, the same dosage produced no effect on the 5-HT efflux in the DRN (Figure 2C,D). Two-way repeated measures ANOVA also showed that the systemic administration of ketamine increased noradrenaline in the mPFC (Figure 3A) as demonstrated by significant effect of treatment $\left(F_{2,10}=10.475, p<0.005\right)$ and treatment $\times$ time interaction $\left(F_{18,99}=2.158, p<0.01\right)$. Results 

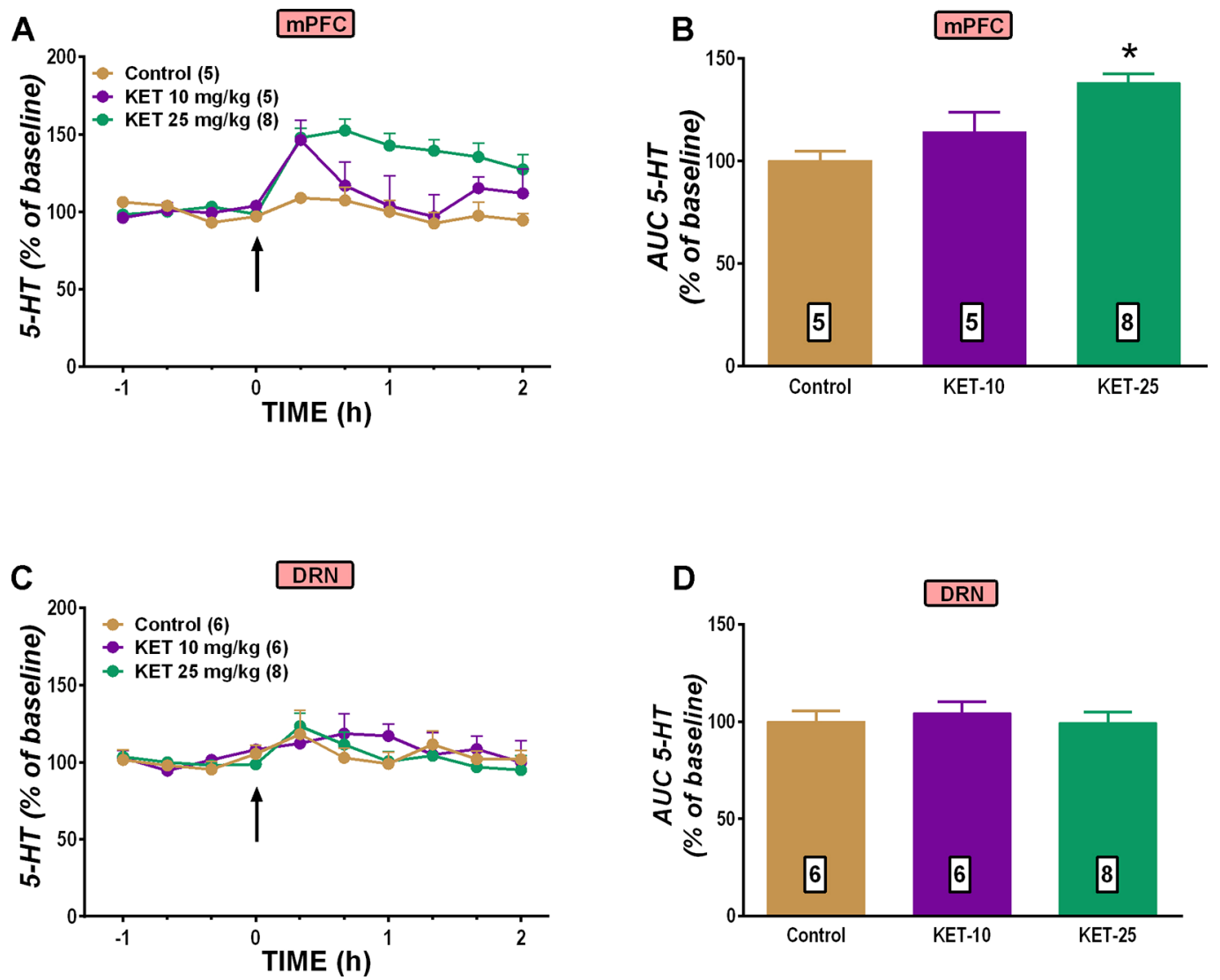

Figure 2. Systemic (i.p.) administration of ketamine (KET) dose-dependently increased dialysate concentration of 5-HT in the $\mathrm{mPFC}(\mathrm{A}, \mathrm{B})$, but had no effect on dialysate 5-HT in the DRN $(\mathrm{C}, \mathrm{D}) .{ }^{*} p<0.002$, post hoc Tukey's multiple comparison tests after significant ANOVA. Number of animals in parentheses and inserted in the bars.

expressed in AUC of the same treatments are represented in Figure 3B. However, no change in dialysate noradrenaline was observed in the DRN after systemic administration of ketamine (Figure 3C,D). Two-way repeated measures ANOVA also showed that the systemic administration of ketamine increased glutamate in the mPFC (Figure 4A) as demonstrated by a significant effect of treatment $\left(F_{2,23}=37.741, p<0.00001\right)$, time $\left(F_{9,207}=3.256, p<0.002\right)$, and treatment $\times$ time interaction $\left(F_{18,207}=2.585, p<0.001\right)$. Results expressed in AUC of the same treatments are represented in Figure $4 \mathrm{~B}$. The systemic administration of ketamine also increased extracellular glutamate in the DRN (Figure 4C), as shown by the significant effect of treatment $\left(F_{2,20}=8.638, p<0.002\right)$, time $\left(F_{9,180}=11.054, p<\right.$ $0.00001)$, and treatment $\times$ time interaction $\left(F_{18,180}=5.690, p<\right.$ 0.00001). Results expressed in AUC of the same treatments are represented in Figure 4D. The local infusion of ketamine (300 $\mu \mathrm{M})$ bilaterally in the mPFC increased locally dialysate noradrenaline (Figure 5A) [significant effect of treatment $\left(F_{3,18}=6.864, p<0.0005\right)$, time $\left(F_{9,162}=5.457, p<0.0001\right)$, and treatment $\times$ time interaction $\left.\left(F_{27,162}=3.078, p<0.0001\right)\right]$, 5-HT (Figure 5C) [significant effect of treatment $\left(F_{3,16}=8.403\right.$, $p<0.005)$, time $\left(F_{9,144}=6.445, p<0.00001\right)$, and treatment $X$ time interaction $\left.\left(F_{27,144}=2.967, p<0.00001\right)\right]$ and glutamate (Figure 5E) [significant effect of treatment $\left(F_{3,20}=9.220, p<\right.$ $0.0005)$, time $\left(F_{9,180}=9.161, p<0.00001\right)$, and treatment $\times$ time interaction $\left.\left(F_{27,180}=4.433, p<0.00001\right)\right]$. The same results expressed in AUC of the treatments are represented in Figures $5 \mathrm{~B}, \mathrm{D}$ and $\mathrm{F}$. In addition, the local infusion of ketamine in the $\mathrm{mPFC}$ increased the extracellular concentration of glutamate in the DRN [significant effect of treatment $\left(F_{1,12}=13.046, p<\right.$ $0.00005)$, time $\left(F_{9,108}=4.018, p<0.0005\right)$, and treatment $\times$ time interaction $\left.\left(F_{9,108}=5.931, p<0.0001\right)\right]$, but not that of 5HT and noradrenaline (Figure 6).

Effects of Ketamine on 8-OH-DPAT-Stimulated $\left[{ }^{35} \mathrm{~S}\right] \mathrm{GTP} \gamma \mathrm{S}$ Binding. Ketamine $(10 \mathrm{mg} / \mathrm{kg})$ was unable to alter the stimulation of $\left[{ }^{35} \mathrm{~S}\right] \mathrm{GTP} \gamma \mathrm{S}$ induced by $8-\mathrm{OH}-\mathrm{DPAT}$ in the DRN (Figure 7).

\section{DISCUSSION}

In this paper, we uncover a possible neurochemical mechanism by which ketamine may exert its rapid antidepressant effects. Here we demonstrated that both systemic and intracortical administration of ketamine elicits a rapid antidepressant-like response in the FST, in line with previous work. ${ }^{29,30}$ In contrast to what results from SSRIs treatment (increased swimming response in rats ${ }^{39}$ ), increased climbing was observed $30 \mathrm{~min}$ after the administration of ketamine, which suggests that the rapid antidepressant-like response of ketamine might be rather due to a stimulation of noradrenaline transmission, which was also found herein. In line with the present results, previous work also reported that subanesthetic doses of ketamine increased the release of not only $5-\mathrm{HT},{ }^{33,34}$ but also noradrenaline ${ }^{40}$ as well as glutamate $^{41}$ in the mPFC. Interestingly, ketamine increased swimming behavior when FST was conducted $24 \mathrm{~h}$ after drug administration, ${ }^{7}$ which concurs with previous work showing that short-term antidepressant response of ketamine is independent of serotonergic transmission. ${ }^{6}$ 
A

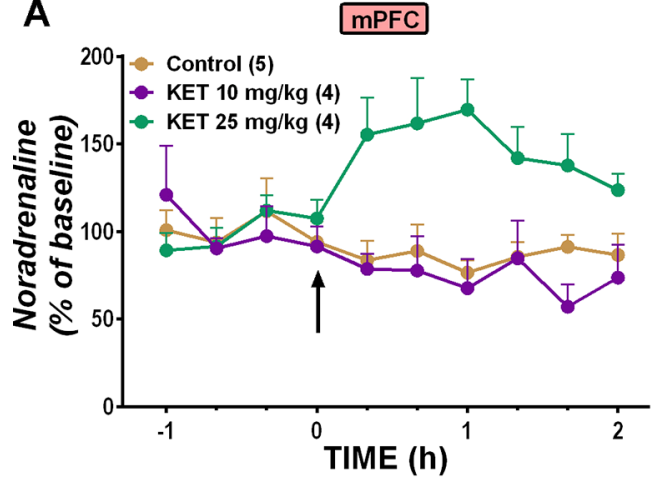

C

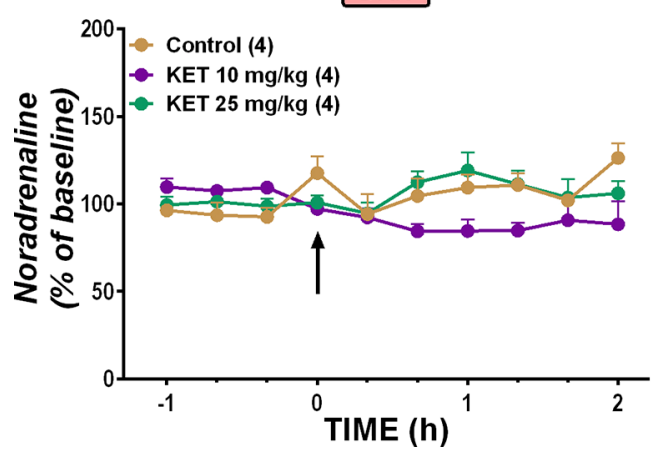

B

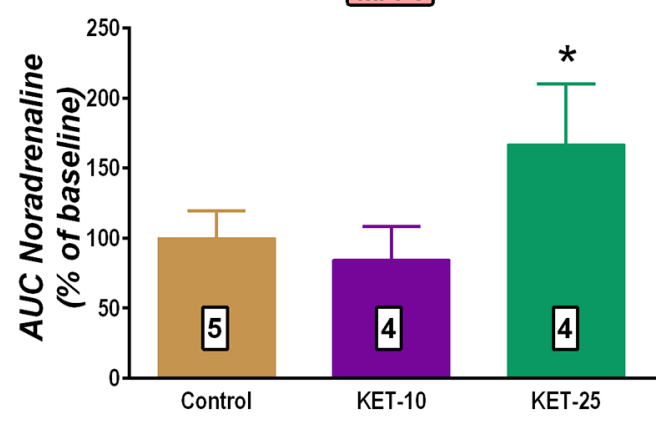

D

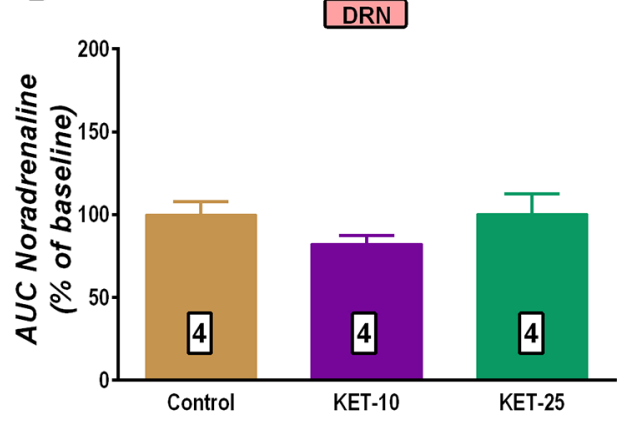

Figure 3. Systemic (i.p.) administration of ketamine (KET) dose-dependently increased dialysate concentration of noradrenaline in the $\mathrm{mPFC}(\mathrm{A}, \mathrm{B})$, but had no effect on dialysate noradrenaline in the DRN (C,D). Only the dose of $25 \mathrm{mg} / \mathrm{kg}$ ketamine elevated extracellular noradrenaline in the mPFC. $*_{p}<0.01$, post hoc Tukey's multiple comparison tests after significant ANOVA. Number of animals in parentheses and inserted in the bars.

It is well-known that SSRIs elevate 5-HT transmission. However, this occurs first in the DRN before taking place in serotonergic nerve endings, ${ }^{42}$ which would act as a brake of inducing forebrain 5-HT release and the subsequent antidepressant response. This effect has been proposed as being responsible of the delayed therapeutic action of these drugs. ${ }^{14}$ Recently, it has been shown that the optogenetic stimulation of prefrontal projection to the DRN evokes antidepressant effects, $^{36-38}$ thus reproducing those elicited by intracortical administration of ketamine. ${ }^{29}$ Interestingly, the systemic administration of ketamine increased substantially 5-HT efflux in the $\mathrm{mPFC}$, but not in the DRN, coincident with previous work in mice ${ }^{7}$ and similarly to what occurs after DBS of the infralimbic cortex. ${ }^{31}$ This absence of alteration in extracellular 5HT in the DRN was coincident with the finding that ketamine was unable to alter the stimulation of $\left[{ }^{35} \mathrm{~S}\right] \mathrm{GTP} \gamma \mathrm{S}$ induced by 8 OH-DPAT in the DRN. This strengthened the notion that ketamine did not modify the function of $5-\mathrm{HT}_{1 \mathrm{~A}}$ autoreceptors in the present experimental conditions, thus suggesting that the autoinhibitory control of raphe $5-\mathrm{HT}_{1 \mathrm{~A}}$ receptors was not altered. Further, systemic ketamine also stimulated the efflux of noradrenaline and glutamate in the mPFC, but only that of glutamate in the DRN. The lack of changes in 5-HT and noradrenaline efflux in the DRN suggests that ketamine do not stimulate evenly all noradrenergic and serotonergic neurons in the locus coeruleus and the DRN, respectively, but only subpopulations of them that project specifically to the mPFC. It has to be noted also that an action of ketamine in other regions that provide stimulatory input to the $\mathrm{DRN}^{43}$ cannot be ruled out. Therefore, we hypothesize that ketamine activates mPFC, layer 5 pyramidal neurons that impact on noradrenergic and serotonergic neurons that project back to the mPFC. Two sets of investigations give further support to our view. First, recent evidence has shown that a subpopulation of mPFC glutamatergic neurons send axonal innervations to the DRN and locus coeruleus and acute pharmacogenetic activation of these neurons has antidepressant-like effects. ${ }^{44}$ Second, ketamine increased AMPA-induced firing activity of pyramidal neurons, ${ }^{45}$ and the activation of such neurons releases glutamate in the DRN that also stimulates AMPA receptors localized to serotonergic neurons, ${ }^{35,46,47}$ which eventually evokes release of serotonin and stimulated $5-\mathrm{HT}_{1 \mathrm{~A}}$ receptors in the mPFC. ${ }^{18}$ Our results further indicate that ketamine also exerts a similar influence upon noradrenergic neurons of the locus coeruleus. Changes in 5-HT and noradrenaline levels cannot be attributed to direct effects of 5-HT and/or noradrenaline transporters as earlier suggested ${ }^{48}$ because recent publications ${ }^{49,50}$ and the $K_{\mathrm{i}}$ database from the National Institute of Mental Health Psychoactive Drug Screening Program (NIMH PDSP, https://pdsp.unc.edu/databases/kidb.php) have distinctly evidenced that ketamine displays no affinity for rat 5-HT and noradrenaline transporters.

The infusion of ketamine directly into the DRN did not change dialysate 5-HT and glutamate in the DRN and mPFC, in line with previous work, ${ }^{35}$ which is concordant with the paucity of NMDA receptors found in this nucleus. ${ }^{51}$ Thus, this is a scenario comparable to what we found following DBS of the infralimbic cortex, i.e., the activation of corticofugal neurons to 

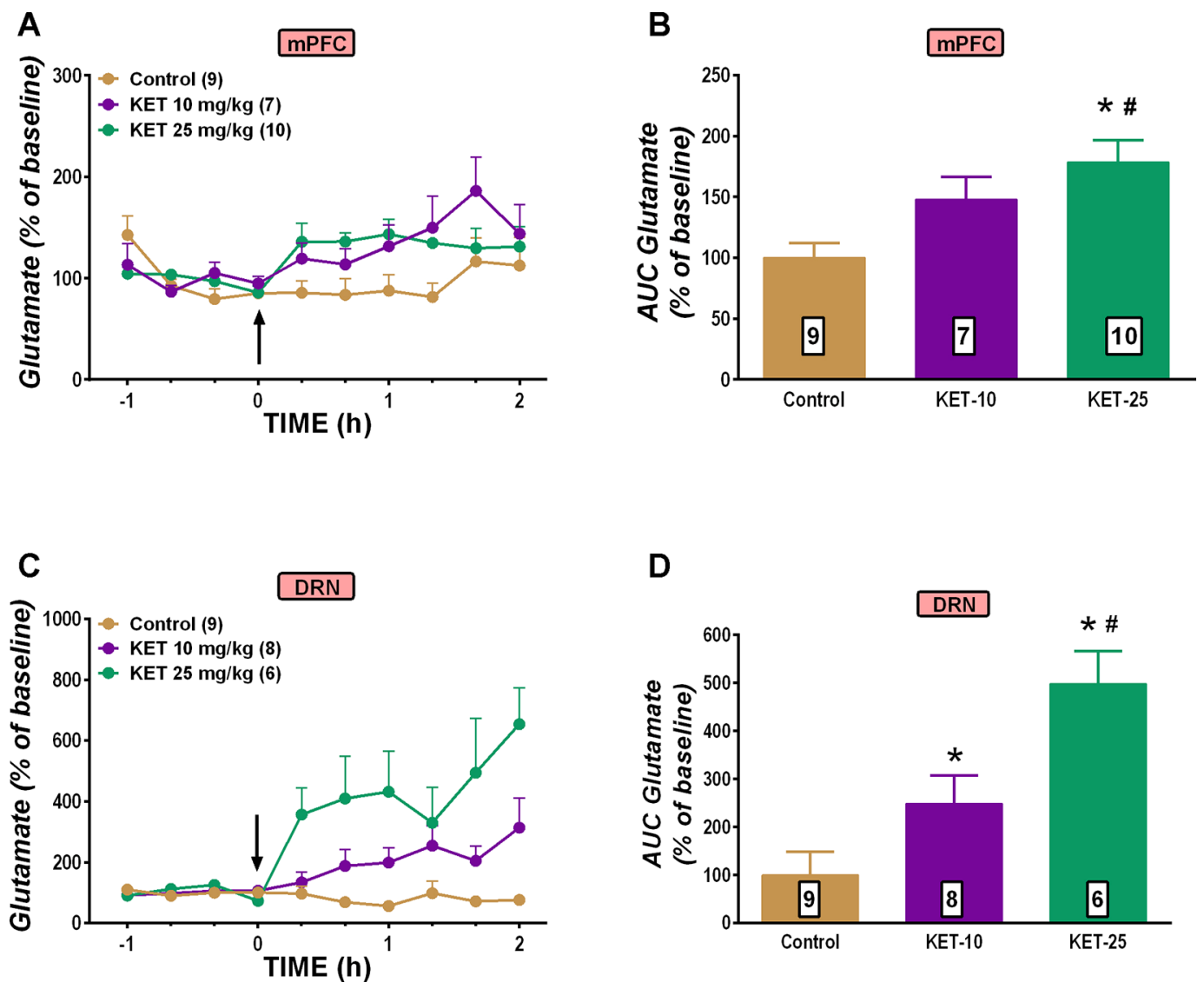

Figure 4. Systemic (i.p.) administration of ketamine (KET) dose-dependently increased dialysate concentration of glutamate in the mPFC (A,B) and in the DRN (C,D). ${ }^{*} p<0.01$ different from control and ${ }^{\#} p<0.05$ different from the dose of $10 \mathrm{mg} / \mathrm{kg}$, post hoc Tukey's multiple comparison tests after significant ANOVA. Number of animals in parentheses and inserted in the bars.

DRN determines the stimulation of serotonergic cells without producing an efflux of 5-HT in the DRN. Further, the systemic ${ }^{52}$ and intra-mPFC ${ }^{31}$ administration of AMPA agonists evoked a rapid antidepressant effect in the FST. In contrast, the infusion of AMPA into the DRN did not produce any local change in the extracellular concentration of 5-HT, ${ }^{35,53}$ but the intra-DRN injection of an AMPA receptor antagonist, abolished the increased efflux of 5-HT in the mPFC after systemic ketamine. ${ }^{35}$ Indeed, both systemic and intracortical administration of ketamine increased the percentage of 5-HT cell bodies in the DRN showing c-Fos immunoreactivity, an effect blocked by microinjection of an AMPA receptor antagonist into the mPFC. ${ }^{30}$ Although further research is needed to ascertain what mechanism is responsible for this particular kind of DRN stimulation, our results are coincident with those of Blier's group showing that enhanced 5-HT neurotransmission can be observed in projection areas after acute ketamine administration without changes in the firing activity of 5-HT neurons in the DRN. ${ }^{45}$ Alternatively, it is also possible that the release of glutamate in the DRN could increase the firing activity of a subset of serotonergic neurons without a concomitant somatodendritic release of 5-HT in the nucleus. The influence upon noradrenergic neurons in the locus coeruleus would have a dissimilar mechanism inasmuch as ketamine did increase noradrenergic firing rate and bursting activity. ${ }^{45}$

\section{CONCLUSION}

In summary, although the monoamine deficiency hypothesis of depression has been questioned, the role of serotonin has regained importance because recent findings show that the sustained antidepressant response of glutamatergic drugs such as ketamine depend upon an intact serotonergic system. In the present work, we suggest that the rapid-antidepressant action of ketamine might rather be due to increased efflux of glutamate and noradrenaline in the $\mathrm{mPFC}$, whereas $5-\mathrm{HT}$ would be responsible for a more sustained effect of the drug.

\section{METHODS}

Animals. Male Wistar rats (Charles River Laboratories, Cerdanyola del Vallès, Spain) weighing 280-350 g (two-month old) were used. The rats were maintained in a controlled environment $(12 \mathrm{~h}$ light/dark cycle, $22 \pm 1{ }^{\circ} \mathrm{C}$ ambient temperature) where food and water were always available. All the experimental procedures were conducted in accordance with national (RD 53/2013) and European legislation (Directive 2010/63/EU, on the Protection of Animals Used for Scientific Purposes, 22 September 2010), and were approved by the Institutional Animal Care and Use Committee of the University of Barcelona.

Drugs and Reagents. Ketamine hydrochloride (Ketolar) was purchased from Pfizer and diluted to appropriate doses (10 and $25 \mathrm{mg}$ / $\mathrm{kg}$ ) with saline for intraperitoneal (i.p.) administration. For intracortical infusion, Ketolar was diluted with artificial cerebrospinal fluid (aCSF, see below for composition) to a concentration of $300 \mu \mathrm{M}$ or $3 \mathrm{mM}$. Standards of noradrenaline, 5-HT, and glutamate, GTP $\gamma$ S and HPLC and other reagents were purchased from Sigma-Aldrich (Tres Cantos, Spain), and 8-OH-DPAT was obtained from Tocris Biosciences (Abingdon, UK). Guanosine-5'-O-(3-[ $\left[{ }^{35} \mathrm{~S}\right]$ thio) triphosphate $\left(\left[{ }^{35} \mathrm{~S}\right]-\right.$ GTP $\gamma$ S) was purchased from PerkinElmer (Waltham, MA).

Forced Swim Test (FST). The FST was conducted as previously described by Cryan and co-workers. ${ }^{54}$ Rats were handled daily for 1 

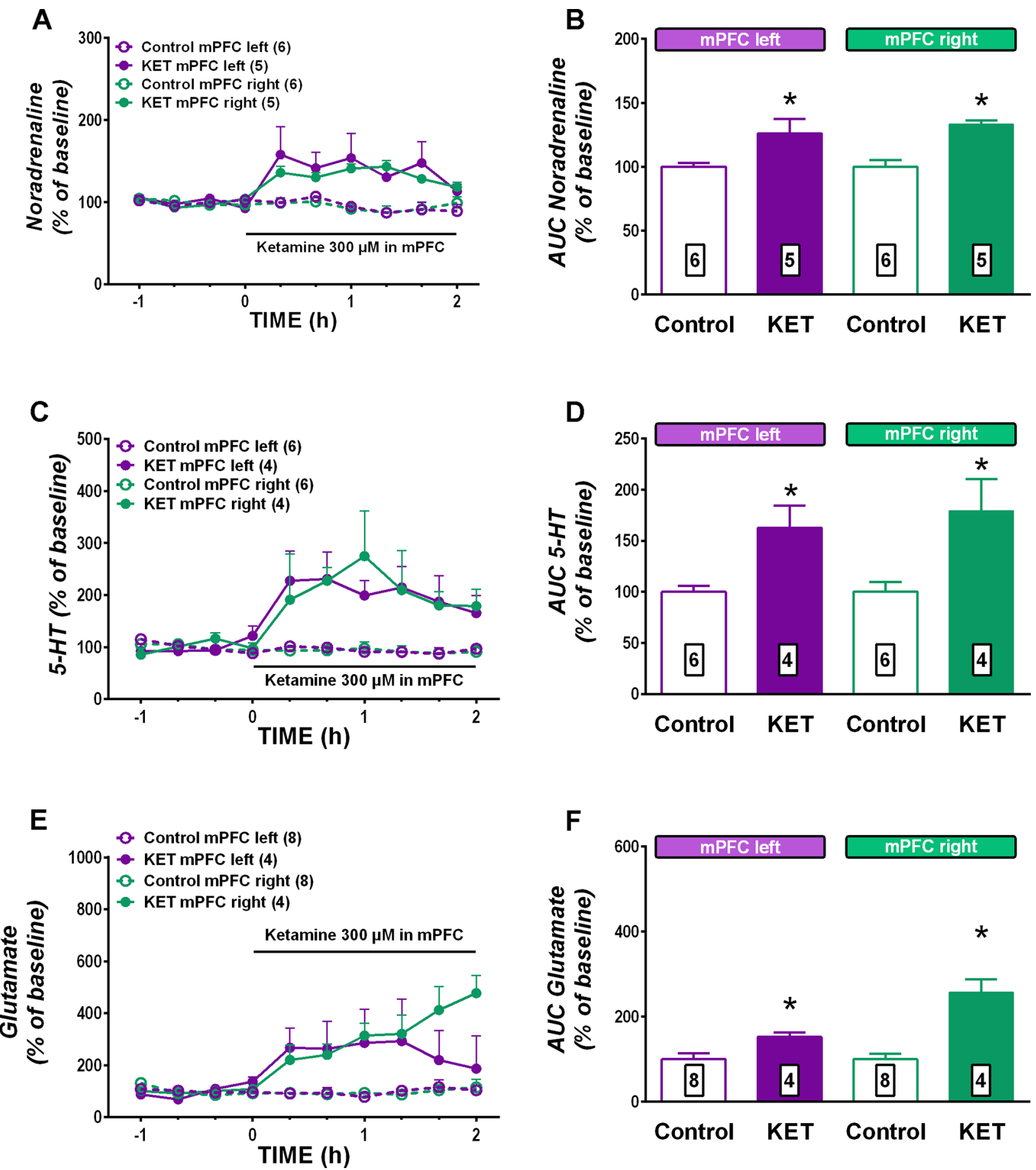

Figure 5. Bilateral intra-mPFC infusion of $300 \mu \mathrm{M}$ ketamine for $2 \mathrm{~h}$ in the mPFC increased the extracellular concentration of noradrenaline (A,B), 5HT $(\mathrm{C}, \mathrm{D})$, and glutamate $(\mathrm{E}, \mathrm{F})$ in the mPFC of both hemispheres. ${ }^{*} p<0.05$, post hoc Tukey's multiple comparison tests after significant ANOVA. Number of animals in parentheses and inserted in the bars.

week before FST. On day 1 (pretest), rats were placed in a clear plexyglas cylinder ( $46 \mathrm{~cm}$ height, $20 \mathrm{~cm}$ diameter) filled with $24 \pm 1{ }^{\circ} \mathrm{C}$ water to a height of $30 \mathrm{~cm}$, for $15 \mathrm{~min}$. After this pretest, animals were returned to their home cages and dried under a lamp for $30 \mathrm{~min}$. The test was conducted and videotaped (ANY maze, Stoelting Europe, Dublin, Ireland) $24 \mathrm{~h}$ after the pretest session in the same cylinder for 5 min immediately following $1 \mathrm{~h}$ perfusion of ketamine bilaterally into the $\mathrm{mPFC}$ or $30 \mathrm{~min}$ after systemic administration of the drug (10 or 25 $\mathrm{mg} / \mathrm{kg}$ ). We chose $30 \mathrm{~min}$ after drug administration because at this time point the effect of ketamine on cortical transmitters is maximal. ${ }^{33,40,41}$ The $5 \mathrm{~min}$ test session was divided into $5 \mathrm{~s}$ epochs. At the end of each epoch the predominant behavior was rated as immobility, climbing and swimming by an experimenter blind to the treatment.

Locomotor Activity. To check for unspecific changes in gross activity that would mask FST observations, locomotor activity was measured in an open field arena $(100 \mathrm{~cm} \times 100 \mathrm{~cm} \times 40 \mathrm{~cm})$ with plastic walls dimly lighted, and recorded during 10 min with a video camera connected to a computer (ANY maze).

Microdialysis Procedures. Concentric dialysis probes with a 4 $\mathrm{mm}$ Cuprophan (pore size $10000 \mathrm{Da}$ ) membrane length were implanted bilaterally under $60 \mathrm{mg} / \mathrm{kg}$ i.p. pentobarbital anesthesia in the $\mathrm{mPFC}(\mathrm{AP}+3.2 \mathrm{~mm}, \mathrm{~L} \pm 0.6 \mathrm{~mm}, \mathrm{DV}-6.0 \mathrm{~mm}$; from bregma), according to reference atlas. ${ }^{55}$ In another set of microdialysis 


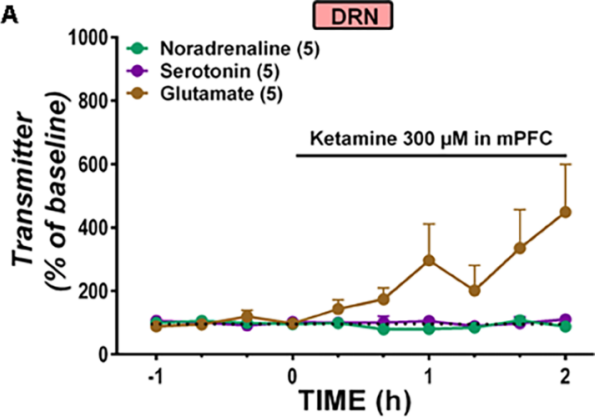

B

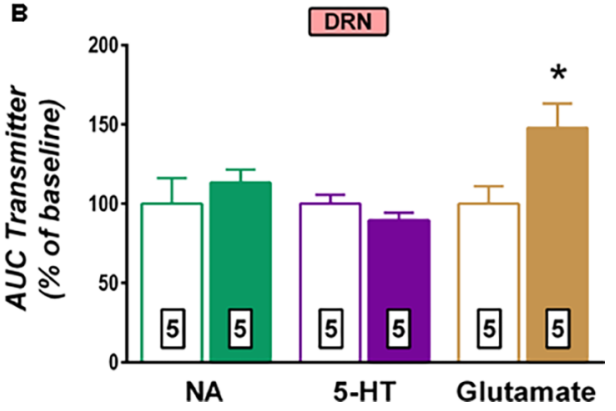

Figure 6. Bilateral intra-mPFC infusion of $300 \mu \mathrm{M}$ ketamine for $2 \mathrm{~h}$ in the $\mathrm{mPFC}$ increased the extracellular concentration of glutamate $(A, B)$, but not that of 5-HT and noradrenaline in the DRN. $*_{p}<0.005$, post hoc Tukey's multiple comparison tests after significant ANOVA. The respective control curves for each transmitter are not shown for the sake of clarity. Instead, a dotted line is represented. Number of animals in parentheses and inserted in the bars.

experiments, two probes were implanted in the $\mathrm{mPFC}$ and a third probe with a $2 \mathrm{~mm}$ Cuprophan membrane length was implanted in the dorsal raphe nucleus (DRN) (AP $-7.8 \mathrm{~mm}, \mathrm{~L}-3.1 \mathrm{~mm}, \mathrm{DV}-7.8 \mathrm{~mm}$, with an angle of $30^{\circ}$ to avoid the aqueduct). Microdialysis experiments were conducted $48 \mathrm{~h}$ after surgery in freely moving rats by continuously perfusing probes with aCSF $\left(147 \mathrm{mM} \mathrm{NaCl}, 3 \mathrm{mM} \mathrm{KCl}, 1.2 \mathrm{mM} \mathrm{CaCl}_{2}\right.$, $1.2 \mathrm{mM} \mathrm{MgCl}_{2}$ ) at a rate of $1 \mu \mathrm{L} / \mathrm{min}$. Dialysate samples of $20 \mu \mathrm{L}$ were collected in microvials containing $5 \mu \mathrm{L}$ of $10 \mathrm{mM}$ perchloric acid, every $20 \mathrm{~min}$. At the completion of experiments, rats were given an overdose of sodium pentobarbital and the brains were then rapidly removed, frozen on dry ice, and stored at $-80{ }^{\circ} \mathrm{C}$. Tissue sections were cut on a cryostat and probe placements were confirmed in histological sections stained with cresyl violet dye. Experimental data from misplaced probes were discarded. Noradrenaline, 5-HT and glutamate were determined using an Alexys Analyzer (Antec Scientific, Leiden, The Netherlands) following manufacturer's methods.

$\left.{ }^{35} \mathrm{~S}\right] \mathrm{GTP} \gamma \mathrm{S}$ Autoradiography of $5-\mathrm{HT}_{1 \mathrm{~A}}$ Receptor Functionality. Coronal brainstem sections ( $14 \mu \mathrm{m}$ thick) were cut at $-20{ }^{\circ} \mathrm{C}$ using a cryostat and thaw-mounted in slides and stored at $-20{ }^{\circ} \mathrm{C}$ until used for $\left[{ }^{35} \mathrm{~S}\right] \mathrm{GTP} \gamma \mathrm{S}$ binding assays. Labeling of brain sections was carried out as described previously ${ }^{56}$ with some modifications. Slidemounted sections were preincubated for $30 \mathrm{~min}$ at room temperature in a buffer containing $50 \mathrm{mM}$ Tris- $\mathrm{HCl}, 0.2 \mathrm{mM}$ EGTA, $3 \mathrm{mM} \mathrm{MgCl}$, 100 $\mathrm{mM} \mathrm{NaCl}, 1 \mathrm{mM}$ DL-dithiothreitol and $2 \mathrm{mM}$ GDP at $\mathrm{pH}=7.7$. Slides were subsequently incubated, for $2 \mathrm{~h}$, in the same buffer containing adenosine deaminase $(10 \mathrm{mU} / \mathrm{mL})$ with $\left[{ }^{35} \mathrm{~S}\right] \mathrm{GTP} \gamma \mathrm{S}(0.04 \mathrm{nM})$, and consecutive sections were also coincubated with 8-OH-DPAT (10 $\mu \mathrm{M})$. Nonspecific binding was determined in the presence of $10 \mu \mathrm{M}$ GTP $\gamma$ S. After the incubation, the sections were washed twice for $15 \mathrm{~min}$ in cold $50 \mathrm{mM}$ Tris- $\mathrm{HCl}$ buffer $(\mathrm{pH}=7.4)$ at $4{ }^{\circ} \mathrm{C}$, rinsed in cold distilled water, and then dried under a cold air stream. Sections were exposed to autoradiographic film (Carestream Health, New York, NY) together with ${ }^{14} \mathrm{C}$ microscales (Amersham) at $4{ }^{\circ} \mathrm{C}$ for 2 days. Autoradiograms were analyzed and quantified using a computerized image analysis system (Scion Image, Scion Corporation, MD). Autoradiographic values of net agonist-stimulated $\left[{ }^{35} \mathrm{~S}\right] \mathrm{GTP} \gamma \mathrm{S}$ binding
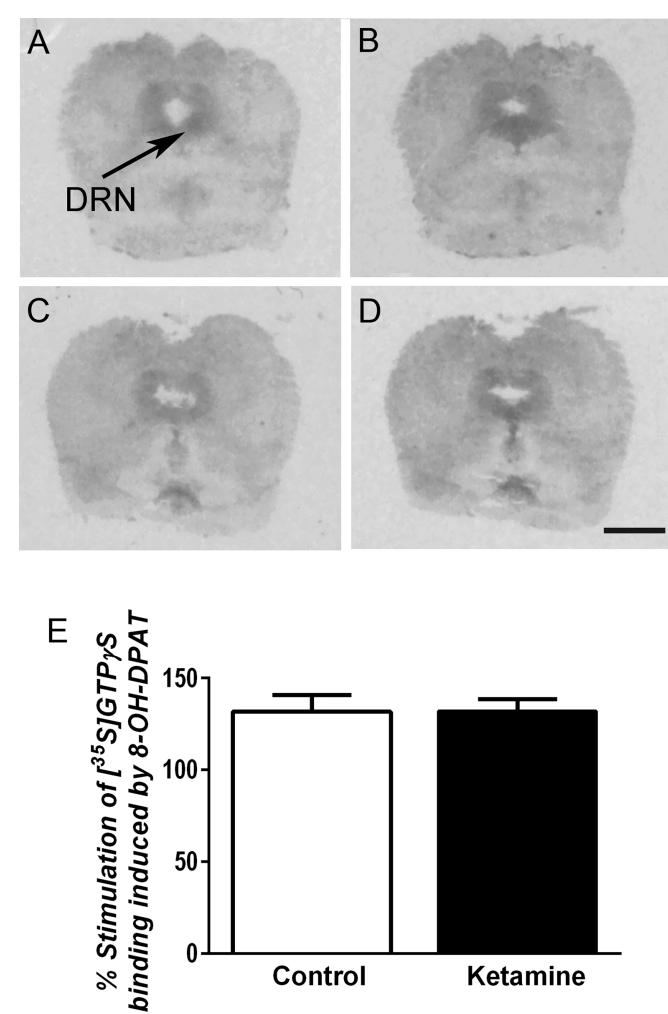

Figure 7. Ketamine did not modify the stimulation of $\left[{ }^{35} \mathrm{~S}\right] \mathrm{GTP} \gamma \mathrm{S}$ induced by the $5-\mathrm{HT}_{1 \mathrm{~A}}$ receptor agonist, 8-OH-DPAT. Midbrain sections showing the basal binding $(A, C)$ and the binding of $\left[{ }^{35} \mathrm{~S}\right] \mathrm{GTP} \gamma \mathrm{S}$ stimulated by $10 \mu \mathrm{M}$ of $8-\mathrm{OH}-\mathrm{DPAT}$ in rats administered with saline $(A, B)$ or ketamine $(C, D)$, respectively. Arrow indicates the localization of dorsal raphe nucleus (DRN). Bar $=2 \mathrm{~mm}$.

were calculated by subtracting basal binding from 8-OH-DPATstimulated binding. Data are expressed as percentage of agoniststimulated binding over basal activity (100\%).

Statistics. Data are expressed as mean \pm SEM. FST data was analyzed by one-way analysis of variance (ANOVA) followed by post hoc Dunnett's tests for each behavior. Unless otherwise specified, microdialysis data were usually analyzed by two-way ANOVA for repeated measures, with treatment and time as main factors, followed by Tukey's post hoc tests. When only two variables were compared, two-tailed Student's $t$ test was used. In all cases, the level of significance was set at $p<0.05$.

\section{ASSOCIATED CONTENT}

\section{Supporting Information}

The Supporting Information is available free of charge on the ACS Publications website at DOI: 10.1021/acschemneur$0.9 \mathrm{~b} 00288$.

Lack of effect of ketamine on locomotor activity measured in an open field arena during $10 \mathrm{~min}$; lack of effect of the infusion of ketamine in the dorsal raphe nucleus on the efflux of 5-HT and glutamate locally and in the mPFC; basal dialysate concentrations of glutamate, noradrenaline, and 5-HT in the medial prefrontal cortex and the dorsal raphe nucleus (PDF)

\section{AUTHOR INFORMATION}

\section{Corresponding Author}

*Mailing address: Institute of Biomedicine and Biotechnology of Cantabria, Calle Albert Einstein 22 (PCTCAN), 39011 
Santander, Spain. Phone: (+34)-942 206857. Fax: $(+34)-942$ 266399. E-mail: albert.adell@unican.es.

\section{ORCID $\odot$}

Albert Adell: 0000-0003-0570-4931

\section{Author Contributions}

X.L.-G. and L.J.-S. contributed equally to this work. X.L.-G., L.J.S., and A.A. carried out microdialysis experiments. E.C. and C.F. carried out $\left[{ }^{35} S\right]$ GTP $\gamma S$ autoradiography. L.C. and A.A. carried out HPLC analyses. X.L.-G., L.J.-S., and A.A. designed the experiments and wrote the manuscript.

\section{Funding}

This work was supported by the Instituto de Salud Carlos III, Subdirección General del Evaluación y Fomento de la Investigación (FIS Grants PI13-00038 and PI16-00217) that were cofunded by the European Regional Development Fund ("A way to build Europe"). Funding from the Centro de Investigación Biomédica en Red de Salud Mental (CIBERSAM) is also acknowledged. We also acknowledge support of the publication fee by the CSIC Open Access Publication Support Initiative through its Unit of Information Resources for Research (URICI).

\section{Notes}

The funding agencies had no role in the design and conduct of the study, collection, management, analyses, and interpretation of the data; and preparation, review, or approval of the manuscript and the decision to submit it for publication. The authors declare no competing financial interest.

\section{REFERENCES}

(1) Holmes, A. (2008) Genetic variation in cortico-amygdala serotonin function and risk for stress-related disease. Neurosci. Biobehav. Rev. 32, 1293-1314.

(2) Nautiyal, K. M., and Hen, R. (2017) Serotonin receptors in depression: from A to B. F1000Research 6, 123.

(3) Loughlin, S. E., Foote, S. L., and Grzanna, R. (1986) Efferent projections of nucleus locus coeruleus: morphologic subpopulations have different efferent targets. Neuroscience 18, 307-319.

(4) Tremblay, P., and Blier, P. (2006) Catecholaminergic strategies for the treatment of major depression. Curr. Drug Targets 7, 149-158.

(5) Hamani, C., Diwan, M., Macedo, C. E., Brandão, M. L., Shumake, J., Gonzalez-Lima, F., Raymond, R., Lozano, A. M., Fletcher, P. J., and Nobrega, J. N. (2010) Antidepressant-like effects of medial prefrontal cortex deep brain stimulation in rats. Biol. Psychiatry 67, 117-124.

(6) Gigliucci, V., O’Dowd, G., Casey, S., Egan, D., Gibney, S., and Harkin, A. (2013) Ketamine elicits sustained antidepressant-like activity via a serotonin-dependent mechanism. Psychopharmacology (Berl) 228, 157-166.

(7) Pham, T. H., Mendez-David, I., Defaix, C., Guiard, B. P., Tritschler, L., David, D. J., and Gardier, A. M. (2017) Ketamine treatment involves medial prefrontal cortex serotonin to induce a rapid antidepressant-like activity in BALB/cJ mice. Neuropharmacology 112, 198-209.

(8) Fava, M. (2003) Diagnosis and definition of treatment-resistant depression. Biol. Psychiatry 53, 649-659.

(9) Ionescu, D. F., Rosenbaum, J. F., and Alpert, J. E. (2015) Pharmacological approaches to the challenge of treatment-resistant depression. Dialogues Clin. Neurosci. 17, 111-126.

(10) Adell, A., and Artigas, F. (1991) Differential effects of clomipramine given locally or systemically on extracellular 5hydroxytryptamine in raphe nuclei and frontal cortex. An in vivo brain microdialysis study. Naunyn-Schmiedeberg's Arch. Pharmacol. 343, 237-244.

(11) Invernizzi, R., Belli, S., and Samanin, R. (1992) Citalopram's ability to increase the extracellular concentrations of serotonin in the dorsal raphe prevents the drug's effect in the frontal cortex. Brain Res. $584,322-324$.

(12) Blier, P., and de Montigny, C. (1994) Current advances and trends in the treatment of depression. Trends Pharmacol. Sci. 15, 220226.

(13) Piñeyro, G., and Blier, P. (1999) Autoregulation of serotonin neurons: role in antidepressant drug action. Pharmacol. Rev. 51, 533591.

(14) Artigas, F., Romero, L., de Montigny, C., and Blier, P. (1996) Acceleration of the effect of selected antidepressant drugs in major depression by 5-HT $\mathrm{HA}_{1 \mathrm{~A}}$ antagonists. Trends Neurosci. 19, 378-383.

(15) Pérez, V., Gilaberte, I., Faries, D., Alvarez, E., and Artigas, F. (1997) Randomised, double-blind, placebo-controlled trial of pindolol in combination with fluoxetine antidepressant treatment. Lancet 349, 1594-1597.

(16) Artigas, F., Celada, P., Laruelle, M., and Adell, A. (2001) How does pindolol improve antidepressant action? Trends Pharmacol. Sci. 22, 224-228.

(17) Blier, P., Bergeron, R., and de Montigny, C. (1997) Selective activation of postsynaptic $5-\mathrm{HT}_{1 \mathrm{~A}}$ receptors induces rapid antidepressant response. Neuropsychopharmacology 16, 333-338.

(18) Fukumoto, K., Iijima, M., Funakoshi, T., and Chaki, S. (2018) Role of 5- $\mathrm{HT}_{1 \mathrm{~A}}$ receptor stimulation in the medial prefrontal cortex in the sustained antidepressant effects of ketamine. Int. J. Neuropsychopharmacol. 21, 371-381.

(19) Richardson-Jones, J. W., Craige, C. P., Guiard, B. P., Stephen, A., Metzger, K. L., Kung, H. F., Gardier, A. M., Dranovsky, A., David, D. J., Beck, S. G., Hen, R., and Leonardo, E. D. (2010) 5-HT ${ }_{1 \mathrm{~A}}$ autoreceptor levels determine vulnerability to stress and response to antidepressants. Neuron 65, 40-52.

(20) Bortolozzi, A., Castañé, A., Semakova, J., Santana, N., Alvarado, G., Cortés, R., Ferrés-Coy, A., Fernández, G., Carmona, M. C., Toth, M., Perales, J. C., Montefeltro, A., and Artigas, F. (2012) Selective siRNA-mediated suppression of 5 - $\mathrm{HT}_{1 \mathrm{~A}}$ autoreceptors evokes strong anti-depressant-like effects. Mol. Psychiatry 17, 612-623.

(21) Berman, R. M., Cappiello, A., Anand, A., Oren, D. A., Heninger, G. R., Charney, D. S., and Krystal, J. H. (2000) Antidepressant effects of ketamine in depressed patients. Biol. Psychiatry 47, 351-354.

(22) Zarate, C. A., Jr, Singh, J. B., Carlson, P. J., Brutsche, N. E., Ameli, R., Luckenbaugh, D. A., Charney, D. S., and Manji, H. K. (2006) A randomized trial of an $\mathrm{N}$-methyl-D-aspartate antagonist in treatmentresistant major depression. Arch. Gen. Psychiatry 63, 856-864.

(23) DiazGranados, N., Ibrahim, L. A., Brutsche, N. E., Ameli, R., Henter, I. D., Luckenbaugh, D. A., Machado-Vieira, R., and Zarate, C. A., Jr. (2010) Rapid resolution of suicidal ideation after a single infusion of an N-methyl-D-aspartate antagonist in patients with treatmentresistant major depressive disorder. J. Clin. Psychiatry 71, 1605-1611.

(24) Singh, J. B., Fedgchin, M., Daly, E. J., De Boer, P., Cooper, K., Lim, P., Pinter, C., Murrough, J. W., Sanacora, G., Shelton, R. C., Kurian, B., Winokur, A., Fava, M., Manji, H., Drevets, W. C., and Van Nueten, L. (2016) A double-blind, randomized, placebo-controlled, dose-frequency study of intravenous ketamine in patients with treatment-resistant depression. Am. J. Psychiatry 173, 816-826.

(25) Maeng, S., Zarate, C. A., Jr, Du, J., Schloesser, R. J., McCammon, J., Chen, G., and Manji, H. K. (2008) Cellular mechanisms underlying the antidepressant effects of ketamine: role of $\alpha$-amino-3-hydroxy-5methylisoxazole-4-propionic acid receptors. Biol. Psychiatry 63, 349352.

(26) Autry, A. E., Adachi, M., Nosyreva, E., Na, E. S., Los, M. F., Cheng, P. F., Kavalali, E. T., and Monteggia, L. M. (2011) NMDA receptor blockade at rest triggers rapid behavioural antidepressant responses. Nature 475, 91-95.

(27) Koike, H., Iijima, M., and Chaki, S. (2011) Involvement of AMPA receptor in both the rapid and sustained antidepressant-like effects of ketamine in animal models of depression. Behav. Brain Res. 224, 107-111.

(28) Li, N., Lee, B., Liu, R. J., Banasr, M., Dwyer, J. M., Iwata, M., Li, X. Y., Aghajanian, G., and Duman, R. S. (2010) mTOR-dependent 
synapse formation underlies the rapid antidepressant effects of NMDA antagonists. Science 329, 959-964.

(29) Fuchikami, M., Thomas, A., Liu, R., Wohleb, E. S., Land, B. B., DiLeone, R. J., Aghajanian, G. K., and Duman, R. S. (2015) Optogenetic stimulation of infralimbic PFC reproduces ketamine's rapid and sustained antidepressant actions. Proc. Natl. Acad. Sci. U. S. A. $112,8106-8111$.

(30) Fukumoto, K., Iijima, M., and Chaki, S. (2016) The antidepressant effects of an $\mathrm{mGlu} 2 / 3$ receptor antagonist and ketamine require AMPA receptor stimulation in the $\mathrm{MPFC}$ and subsequent activation of the 5-HT neurons in the DRN. Neuropsychopharmacology $41,1046-1056$.

(31) Jiménez-Sánchez, L., Castañé, A., Pérez-Caballero, L., GrifollEscoda, M., López-Gil, X., Campa, L., Galofré, M., Berrocoso, E., and Adell, A. (2016) Activation of AMPA receptors mediates the antidepressant action of deep brain stimulation of the infralimbic prefrontal cortex. Cereb. Cortex 26, 2778-2789.

(32) Gasull-Camós, J., Tarrés-Gatius, M., Artigas, F., and Castañé, A. (2017) Glial GLT-1 blockade in infralimbic cortex as a new strategy to evoke rapid antidepressant-like effects in rats. Transl. Psychiatry 7, e1038.

(33) Amargós-Bosch, M., López-Gil, X., Artigas, F., and Adell, A. (2006) Clozapine and olanzapine, but not haloperidol, suppress serotonin efflux in the medial prefrontal cortex elicited by phencyclidine and ketamine. Int. J. Neuropsychopharmacol. 9, 565-573.

(34) López-Gil, X., Jiménez-Sánchez, L., Romón, T., Campa, L., Artigas, F., and Adell, A. (2012) Importance of inter-hemispheric prefrontal connection in the effects of non-competitive NMDA receptor antagonists. Int. J. Neuropsychopharmacol. 15, 945-956.

(35) Nishitani, N., Nagayasu, K., Asaoka, N., Yamashiro, M., Shirakawa, H., Nakagawa, T., and Kaneko, S. (2014) Raphe AMPA receptors and nicotinic acetylcholine receptors mediate ketamineinduced serotonin release in the rat prefrontal cortex. Int. J. Neuropsychopharmacol. 17, 1321-1326.

(36) Covington, H. E., 3rd, Lobo, M. K., Maze, I., Vialou, V., Hyman, J. M., Zaman, S., LaPlant, Q., Mouzon, E., Ghose, S., Tamminga, C. A., Neve, R. L., Deisseroth, K., and Nestler, E. J. (2010) Antidepressant effect of optogenetic stimulation of the medial prefrontal cortex. J. Neurosci. 30, 16082-16090.

(37) Warden, M. R., Selimbeyoglu, A., Mirzabekov, J. J., Lo, M., Thompson, K. R., Kim, S. Y., Adhikari, A., Tye, K. M., Frank, L. M., and Deisseroth, K. (2012) A prefrontal cortex-brainstem neuronal projection that controls response to behavioural challenge. Nature 492, 428-432.

(38) Challis, C., Beck, S. G., and Berton, O. (2014) Optogenetic modulation of descending prefrontocortical inputs to the dorsal raphe bidirectionally bias socioaffective choices after social defeat. Front. Behav. Neurosci. 8, 43.

(39) Lucki, I. (1997) The forced swimming test as a model for core and component behavioral effects of antidepressant drugs. Behav. Pharmacol. 8, 523-32.

(40) Lorrain, D. S., Schaffhauser, H., Campbellm, U. C., Baccei, C. S., Correa, L. D., Rowe, B., Rodriguez, D. E., Anderson, J. J., Varney, M. A., Pinkerton, A. B., Vernier, J. M., and Bristow, L. J. (2003) Group II mGlu receptor activation suppresses norepinephrine release in the ventral hippocampus and locomotor responses to acute ketamine challenge. Neuropsychopharmacology 28, 1622-1632.

(41) Moghaddam, B., Adams, B., Verma, A., and Daly, D. (1997) Activation of glutamatergic neurotransmission by ketamine: a novel step in the pathway from NMDA receptor blockade to dopaminergic and cognitive disruptions associated with the prefrontal cortex. $J$. Neurosci. 17, 2921-2927.

(42) Hervás, I., and Artigas, F. (1998) Effect of fluoxetine on extracellular 5-hydroxytryptamine in rat brain. Role of 5-HT autoreceptors. Eur. J. Pharmacol. 358, 9-18.

(43) Kinoshita, H., Nishitani, N., Nagai, Y., Andoh, C., Asaoka, N., Kawai, H., Shibui, N., Nagayasu, K., Shirakawa, H., Nakagawa, T., and Kaneko, S. (2018) Ketamine-induced prefrontal serotonin release is mediated by cholinergic neurons in the pedunculopontine tegmental nucleus. Int. J. Neuropsychopharmacol. 21, 305-310.

(44) Soiza-Reilly, M., Meye, F. J., Olusakin, J., Telley, L., Petit, E., Chen, X., Mameli, M., Jabaudon, D., Sze, J. Y., and Gaspar, P. (2019) SSRIs target prefrontal to raphe circuits during development modulating synaptic connectivity and emotional behavior. Mol. Psychiatry 24, 726-745.

(45) El Iskandrani, K. S., Oosterhof, C. A., El Mansari, M., and Blier, P. (2015) Impact of subanesthetic doses of ketamine on AMPA-mediated responses in rats: An in vivo electrophysiological study on monoaminergic and glutamatergic neurons. J. Psychopharmacol. 29, 792-801.

(46) Gartside, S. E., Cole, A. J., Williams, A. P., McQuade, R., and Judge, S. J. (2007) AMPA and NMDA receptor regulation of firing activity in 5-HT neurons of the dorsal and median raphe nuclei. Eur. J. Neurosci. 25, 3001-3008.

(47) Geddes, S. D., Assadzada, S., Lemelin, D., Sokolovski, A., Bergeron, R., Haj-Dahmane, S., and Béïque, J. C. (2016) Target-specific modulation of the descending prefrontal cortex inputs to the dorsal raphe nucleus by cannabinoids. Proc. Natl. Acad. Sci. U. S. A. 113, 54295434.

(48) Hara, K., Yanagihara, N., Minami, K., Ueno, S., Toyohira, Y., Sata, T., Kawamura, M., Brüss, M., Bönisch, H., Shigematsu, A., and Izumi, F. (1998) Ketamine interacts with the noradrenaline transporter at a site partly overlapping the desipramine binding site. Naunyn-Schmiedeberg's Arch. Pharmacol. 358, 328-333.

(49) Sałat, K., Siwek, A., Starowicz, G., Librowski, T., Nowak, G., Drabik, U., Gajdosz, R., and Popik, P. (2015) Antidepressant-like effects of ketamine, norketamine and dehydronorketamine in forced swim test: Role of activity at NMDA receptor. Neuropharmacology 99, 301-307.

(50) Can, A., Zanos, P., Moaddel, R., Kang, H. J., Dossou, K. S., Wainer, I. W., Cheer, J. F., Frost, D. O., Huang, X. P., and Gould, T. D. (2016) Effects of ketamine and ketamine metabolites on evoked striatal dopamine release, dopamine receptors, and monoamine transporters. J. Pharmacol. Exp. Ther. 359, 159-170.

(51) Soiza-Reilly, M., and Commons, K. G. (2011) Glutamatergic drive of the dorsal raphe nucleus. J. Chem. Neuroanat. 41, 247-255.

(52) Akinfiresoye, L., and Tizabi, Y. (2013) Antidepressant effects of AMPA and ketamine combination: role of hippocampal BDNF, synapsin, and mTOR. Psychopharmacology (Berl) 230, 291-298.

(53) Tao, R., Ma, Z., and Auerbach, S. B. (1997) Influence of AMPA/ kainate receptors on extracellular 5-hydroxytryptamine in rat midbrain raphe and forebrain. Br. J. Pharmacol. 121, 1707-1715.

(54) Cryan, J. F., Valentino, R. J., and Lucki, I. (2005) Assessing substrates underlying the behavioral effects of antidepressants using the modified rat forced swimming test. Neurosci. Biobehav. Rev. 29, 547569.

(55) Paxinos, G., and Watson, C. (2008) The Rat Brain in Stereotaxic Coordinates, Academic Press, San Diego, CA.

(56) Amigó, J., Díaz, A., Pilar-Cuéllar, F., Vidal, R., Martín, A., Compan, V., Pazos, A., and Castro, E. (2016) The absence of 5-HT receptors modulates depression- and anxiety-like responses and influences the response of fluoxetine in olfactory bulbectomised mice: Adaptive changes in hippocampal neuroplasticity markers and 5$\mathrm{HT}_{1 \mathrm{~A}}$ autoreceptor. Neuropharmacology 111, 47-58. 